\title{
Seasonal changes in spatial variation of soil respiration in dry evergreen forest, Sakaerat Biosphere Reserve, Thailand
}

\author{
Warin Boonriam $^{\mathrm{a}}$, Pongthep Suwanwaree ${ }^{\mathrm{a}, *}$, Sasitorn Hasin $^{\mathrm{b}}$, Taksin Archawakom ${ }^{\mathrm{c}}$, \\ Phuvasa Chanonmuang ${ }^{\mathrm{d}}$, Akinori Yamada ${ }^{\mathrm{e}, \mathrm{f}}$ \\ a School of Biology, Institute of Science, Suranaree University of Technology, Nakhon Ratchasima 30000 \\ Thailand \\ b Innovation of Environmental Management, College of Innovative Management, Valaya Alongkorn \\ Rajabhat University under the Royal Patronage, Pathum Thani 13180 Thailand \\ c Sakaerat Environmental Research Station, Nakhon Ratchasima 30370 Thailand \\ d Expert Centre of Innovation Clean Energy and Environment, Thailand Institute of Scientific and \\ Technological Research, Pathum Thani 12120 Thailand \\ e Department of Biological Sciences, Tokyo Institute of Technology, Tokyo 226-8501 Japan \\ f Graduate School of Fisheries and Environmental Sciences, Nagasaki University, Nagasaki 852-8521 \\ Japan
}

*Corresponding author, e-mail: pongthep@sut.ac.th

Received 10 Nov 2020

Accepted 28 Apr 2021

\begin{abstract}
Soil respiration in tropical forests is an important source of carbon dioxide in the atmosphere. Factors regulating spatial soil respiration are still unclear, and they may lead to an inaccurate estimation of soil respiration at the ecosystem level. The aim of this study was to investigate the seasonal changes in spatial variation of soil respiration in a dry evergreen forest of Sakaerat Biosphere Reserve, Nakhon Ratchasima Province, Thailand. Soil respiration, temperature, and moisture were measured in 100 subplots of five 1-ha main plots for four times from November 2014 to August 2016. The average rate $\left( \pm \mathrm{SD}\right.$ ) of annual aboveground soil respiration was $6.57 \pm 4.29 \mu \mathrm{mol} \mathrm{CO}_{2} \mathrm{~m}^{-2} \mathrm{~s}^{-1}$. Soil respiration considerably varied with space and time. The mean ranges were from 2.66 to $11.72 \mu \mathrm{mol} \mathrm{CO}_{2} \mathrm{~m}^{-2} \mathrm{~s}^{-1}$ with a maximum rate of $42.68 \mu \mathrm{mol} \mathrm{CO} \mathrm{m}^{-2} \mathrm{~s}^{-1}$. The wet season soil respiration rate $\left(8.81 \mu \mathrm{mol} \mathrm{CO} \mathrm{C}^{-2} \mathrm{~s}^{-1}\right) \mathrm{was}$ two times higher $(p<0.001)$ than in the dry season $\left(4.33 \mu \mathrm{mol} \mathrm{CO} \mathrm{m}^{-2} \mathrm{~s}^{-1}\right)$. The seasonal changes clearly affected the spatial variation of soil respiration. Wet season produced higher and more widespread soil respiration. Although soil respiration rates increase with increasing soil temperature and soil moisture content, the rate starts to drop at $27^{\circ} \mathrm{C}$ soil temperature $(p<0.001)$ and $21 \%$ soil moisture content $(p<0.05)$. This study suggests more investigation of soil features and animal influences on $\mathrm{CO}_{2}$ emission hot spots in order to accurately estimate soil respiration in tropical forests.
\end{abstract}

KEYWORDS: soil respiration, $\mathrm{CO}_{2}$ efflux, spatial variability, seasonal tropical forest

\section{INTRODUCTION}

An important component of the global $\mathrm{CO}_{2}$ balance has been recognized as $\mathrm{CO}_{2}$ emission from the soil (soil respiration). Indeed, soil respiration is the second largest terrestrial carbon flux in the forest ecosystems, which contributes $50-95 \%$ of the total ecosystem respiration $[1,2]$. Tropical forest is an important contributor to the global carbon cycle through storing $45 \%$ of global terrestrial carbon stocks in vegetation [3]. Generally, compared with boreal and temperate forests, tropical forests have higher rates and variations of soil respiration [4]. Thus, tropical forests could strongly influence future $\mathrm{CO}_{2}$ concentrations in the atmosphere. However, the range of variability in soil respiration from tropical forests remains difficult to assess, and it may lead to inaccurate soil respiration estimates at the ecosystem level.

Soil respiration comes from $\mathrm{CO}_{2}$ production of all living organisms in the soil, including plant roots, soil microbes, and animals $[5,6]$. In tropical forests, soil $\mathrm{CO}_{2}$ emission showed strong seasonal variations with higher rates in the hot humid seasons and 


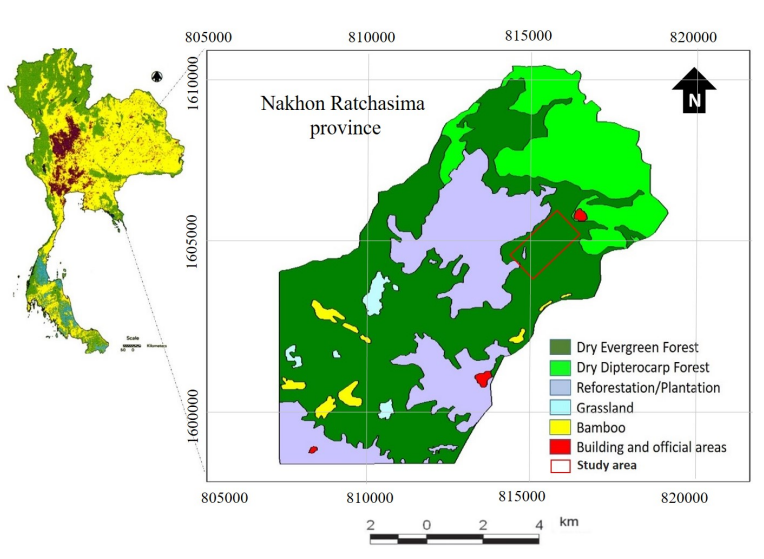

Fig. 1 The study site in DEF at SERS.

lower values in the cool dry seasons [7]. Although soil microorganisms and plant roots dominantly constitute soil respiration, published data reported that root/rhizosphere respiration is responsible for $10-90 \%$ of total soil respiration [8]. The rate of soil respiration has been shown to change and fluctuate at an unexpectedly large scale. It was quite difficult to be explained by known environmental factors, such as soil water content and temperature. In order to accurately estimate soil respiration in the forest ecosystems, it is essential to have information on spatial and temporal variability for estimating the average rate of soil respiration at regional scales.

The annual and seasonal dynamics of soil respiration is preferably considered by the spatial distribution patterns. Seasonal tropical forests occasionally encounter climate fluctuations; therefore, this study aimed to investigate the spatial and seasonal patterns of soil respiration at plot-scale in a seasonal tropical forest at Sakaerat Biosphere Reserve, Nakhon Ratchasima, Thailand.

\section{MATERIALS AND METHODS}

Study site

Field studies were performed in the dry evergreen forest (DEF) at Sakaerat Environmental Research Station (SERS) $\left(14^{\circ} 30^{\prime} \mathrm{N}, 101^{\circ} 56^{\prime} \mathrm{E}\right.$; about $500 \mathrm{~m}$ above sea level) in Nakhon Ratchasima Province, Northeastern Thailand (Fig. 1). The study period was from November 2014 to August 2016, with dry season from November to March and wet season from May to October. The total annual rainfall was $1751.2 \mathrm{~mm}$, and monthly rainfall was less than $40 \mathrm{~mm}$ during the dry season. The average percentage of relative humidity, evaporation, and annual temperature were $74 \%, 1.2 \mathrm{~mm}$, and $26.7^{\circ} \mathrm{C}$
(7.9-40.6 $6^{\circ} \mathrm{C}$, respectively. The DEF covers an area of $29.5 \mathrm{~km}^{2}$, where the dominant tree species are Hopea ferrea and Hopea odorata with canopy trees reaching generally 23 to $40 \mathrm{~m}$ in height [9]. Litterfall accumulated on the forest floor was approximately $25 \mathrm{t} / \mathrm{ha}$, and the thickness of litter layer was $2-5 \mathrm{~cm}[10]$.

\section{Field study design and measurements of soil $\mathrm{CO}_{2}$, temperature, and moisture}

Soil respiration was measured in 5 main plots $\left(100 \times 100 \mathrm{~m}^{2}\right)$, and each plot was divided into 100 subplots $\left(10 \times 10 \mathrm{~m}^{2}\right)$. The measurement points were at the center of individual subplots. The plots were established at different locations in the DEF according to the vegetation, elevation, and soil characteristics. Soil respiration were observed two times for each season; November to December 2014 and March 2016 for dry season and October 2015 and July to August 2016 for wet season.

At the measurement point, a PVC collar $(10 \mathrm{~cm}$ in diameter and ca. $3 \mathrm{~cm}$ in height) was placed at least one day before the measurement to avoid disturbing soil activities. $\mathrm{CO}_{2}$ emissions were measured using a portable infrared gas analyzer (IRGA, EGM-4, PP Systems, Hitchin, UK) with a closed soil $\mathrm{CO}_{2}$ efflux chamber (diameter $10 \mathrm{~cm}$; SRC-1, PP Systems). Immediately after $\mathrm{CO}_{2}$ measurement, soil temperature and soil moisture were measured around the PVC collar at about $10 \mathrm{~cm}$ depth using a digital thermometer waterproof probe (types H-1 and H-2, Shinwa Co., Ltd., Japan) and a soil moisture sensor (SM150, Delta-T Devices Ltd., Cambridge, UK). The measurements took 3 to $5 \mathrm{~min}$ per 1 point and started from 9:00 am until 6:00 pm in normal condition without rainfall.

\section{Statistical analysis}

Soil respiration was assessed as the mean, skewness, range, and standard deviation using the frequency distribution from 2000 sampling data. For all analyses, the normality and homogeneity were tested by the Kolmogorov-Smirnov test. The significant differences in $\mathrm{CO}_{2}$ effluxes among the seasons were tested by a Student's $t$-test. Also, the relationship of soil respiration between dry and wet seasons was tested by Pearson's correlation. In both seasons, the spatial distribution pattern maps of $\mathrm{CO}_{2}$ emission, temperature, and moisture from the soil were created using the MATLAB program. The relationship between $\mathrm{CO}_{2}$ effluxes and environmental factors (soil temperature and moisture) was tested by linear 


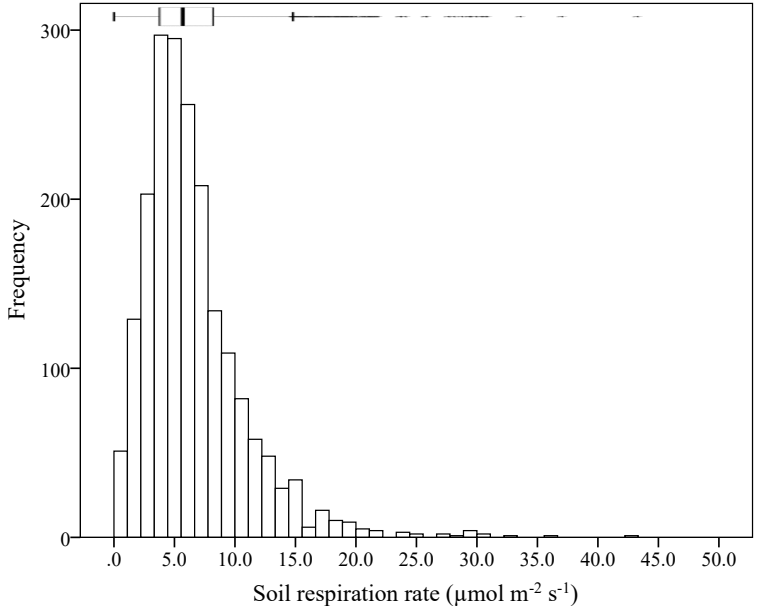

Fig. 2 Frequency distribution of soil respiration rates from the five main plots in DEF. The box plot above indicates the median as a vertical line is drawn at the box between the distributions of data set. The "whiskers" on the left and the right of the box show the locations of the minimum and maximum respiration rates, respectively.

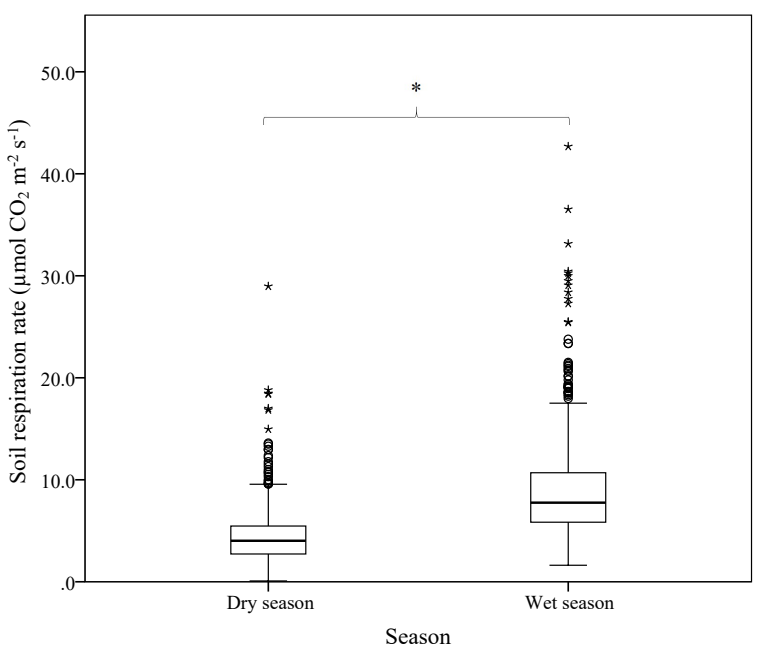

Fig. 3 Box plot showing the variability of soil respiration rates in the dry and wet seasons. Significant difference between dry and wet seasons using Student's $t$-test $(p<$ 0.001 ) is indicated by asterisks.

regression analysis. All statistical calculations were performed in SPSS ver. 20.0.0 for Windows.

\section{RESULTS AND DISCUSSION}

\section{Temporal variation in soil respiration}

The temporal pattern of soil respiration was seasonal and changed with the fluctuation range of soil temperature and soil moisture. The overall mean of soil respiration rate $( \pm \mathrm{SD})$ was $6.57 \pm 4.29 \mu \mathrm{mol}$ $\mathrm{CO}_{2} \mathrm{~m}^{-2} \mathrm{~s}^{-1}$, with variation mean from the five plots ranged from 2.66 to $11.72 \mu \mathrm{mol} \mathrm{CO}_{2} \mathrm{~m}^{-2} \mathrm{~s}^{-1}$. The distribution estimates of soil respiration rates displayed a positively skewed frequency distribution with a skewness of $2.06 \pm 0.05$. The minimum and maximum rates were 0.08 and $42.68 \mu \mathrm{mol} \mathrm{CO}_{2}$ $\mathrm{m}^{-2} \mathrm{~s}^{-1}$, respectively (Fig. 2 ). The mean value of soil respiration rates from this study $(6.57 \pm 4.29 \mu \mathrm{mol}$ $\mathrm{CO}_{2} \mathrm{~m}^{-2} \mathrm{~s}^{-1}$ ) was quite similar to the results of 6.05 and $6.76 \mu \mathrm{mol} \mathrm{CO} \mathrm{m}^{-2} \mathrm{~s}^{-1}$, respectively obtained from DEF in Kog-Ma Experimental Watershed, Northern Thailand [7] and Huai Kha Khaeng Wildlife Sanctuary, Western Thailand [11]; but almost 3 times higher than the value obtained from the dry dipterocarp forest in Western Thailand [12]. Moreover, the value from this study was in the range of soil respiration $\left(1.8-6.8 \mu \mathrm{mol} \mathrm{CO}_{2} \mathrm{~m}^{-2} \mathrm{~s}^{-1}\right.$ ) reported from tropical forests in Thailand, Central Amazon [13], and Malaysia [14].

The seasonal variation of soil respiration showed a significant difference between dry and wet seasons ( $p<0.001$; Fig. 3$)$. The mean respiration rate in the wet season was significantly two times higher $\left(8.8 \pm 4.5 \mu \mathrm{mol} \mathrm{CO}_{2} \mathrm{~m}^{-2} \mathrm{~s}^{-1}\right)$ than in the dry season $\left(4.3 \pm 2.5 \mu \mathrm{mol} \mathrm{CO} \mathrm{m}^{-2} \mathrm{~s}^{-1}\right)$. The average soil temperatures also significantly differed between dry and wet seasons $\left(24.7 \pm 0.7^{\circ} \mathrm{C}\right.$ and $25.0 \pm 0.4^{\circ} \mathrm{C}$, respectively), but the difference is less than $1^{\circ} \mathrm{C}$. In addition, the average soil moisture content in the wet season $(18.4 \pm 0.4 \%)$ was significantly higher than in the dry season $(7.0 \pm 0.8 \%)$. Therefore, the results from this study demonstrated that soil moisture is a major factor contributing to increase soil respiration. When compared with another study done in 1982 at the same site as this study, the rates of soil respiration were much lower in both seasons, especially in the dry season [15]. In the 1982 study, the soil respiration rates in the dry and the wet seasons were 2.4 and $7.3 \mu \mathrm{mol} \mathrm{CO} \mathrm{Cm}^{-2} \mathrm{~s}^{-1}$ with the average soil temperatures of $20.2^{\circ} \mathrm{C}$ and $23.1^{\circ} \mathrm{C}$, respectively. The lower temperature and thus lower soil respiration were due to a factor that the study was conducted in a colder year.

\section{Spatial variation in soil respiration}

Soil respiration considerably varied with space. The spatial distribution map, as well as the frequency distribution, expressed the uneven and unusual rates of $\mathrm{CO}_{2}$ efflux as extremely high over $40 \mu \mathrm{mol}$ $\mathrm{CO}_{2} \mathrm{~m}^{-2} \mathrm{~s}^{-1}$ (Fig. 4). These $\mathrm{CO}_{2}$ "hot spots" were found in many locations in the main plots. Some hot spots persisted in both seasons but with higher 
(a)

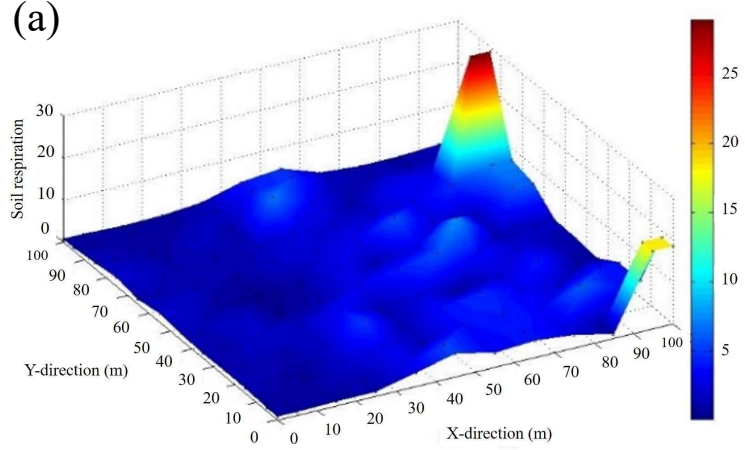

(c)

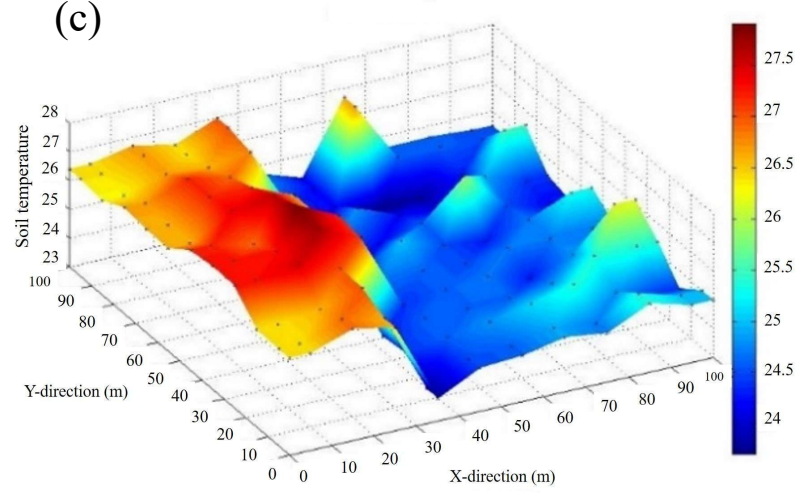

(e)

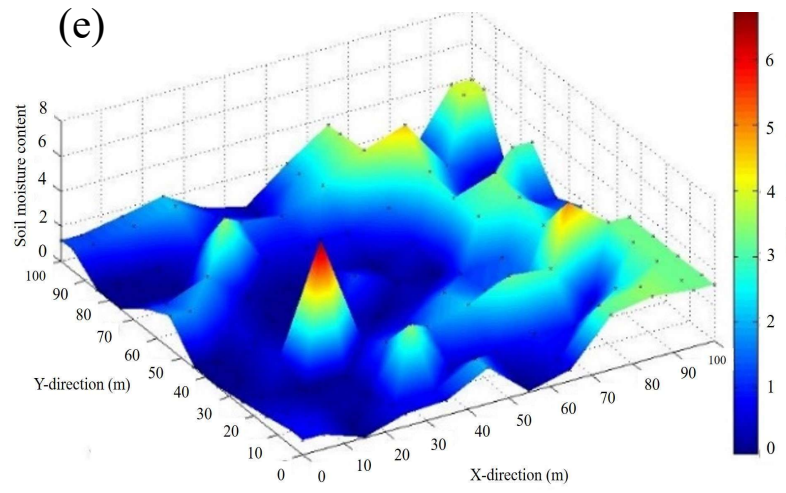

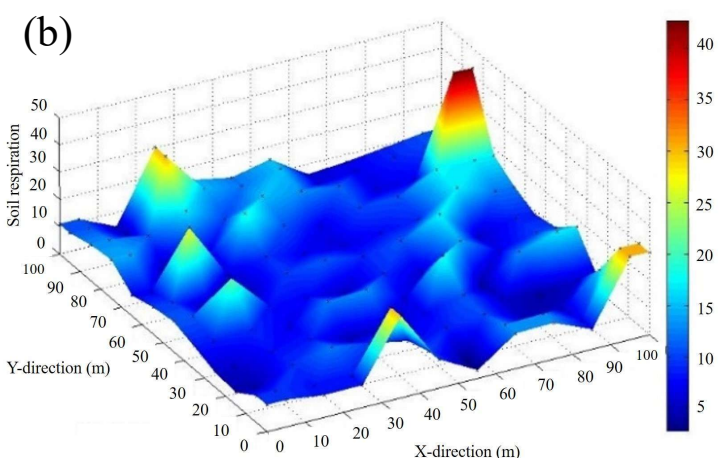

(d)

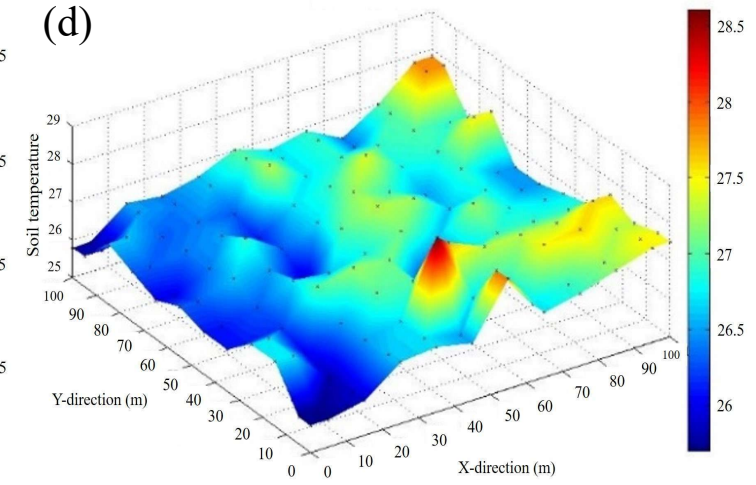

(f)

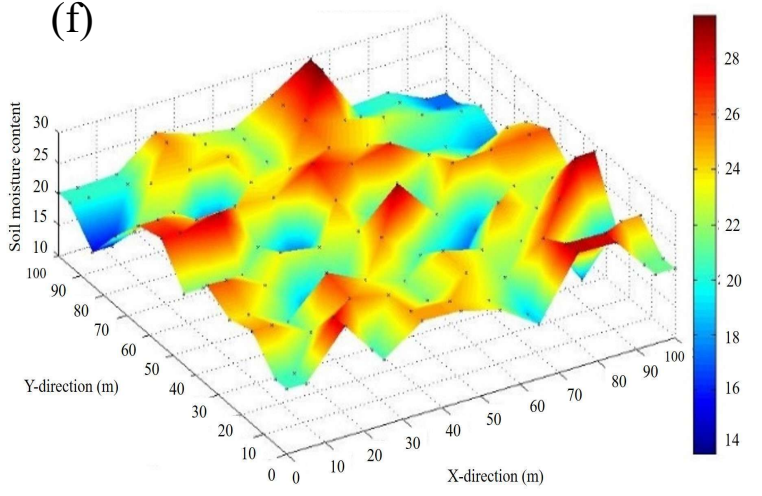

Fig. 4 Examples of soil respiration distribution maps in dry (a) and wet (b) seasons, soil temperature distribution in dry (c) and wet (d) seasons, and soil moisture distribution in dry (e) and wet (f) seasons.

magnitude in the wet season. In addition, greater distribution of higher soil respiration subplots was shown in the wet season than in the dry season. The correlation of soil respiration between dry and wet seasons was significant and slightly positive $(p<$ $0.01 ; R=0.228$; Fig. 5 ). Therefore, soil respirations of the same locations tend to produce more $\mathrm{CO}_{2}$ in the wet season.

The spatial distribution of soil respiration apparently could not be explained by soil temperature distribution even though it quite coincided with the distribution of soil moisture (Fig. 4). However, both factors could limit soil respiration at some point. The spatial variation of soil respiration could be influenced by other factors, such as soil texture, soil organic matter, soil organic carbon, and especially soil animals. The spatial fluctuation in soil respiration in this study, especially the hot spot locations, was possibly caused by subterranean nests of ants and termites because these insects are highly abundant in number and biomass in the tropical forests. Ohashi et al $[14,16]$ indicated that subterranean nests of ants and termites were the main causes of the extremely high rates of soil respiration as 


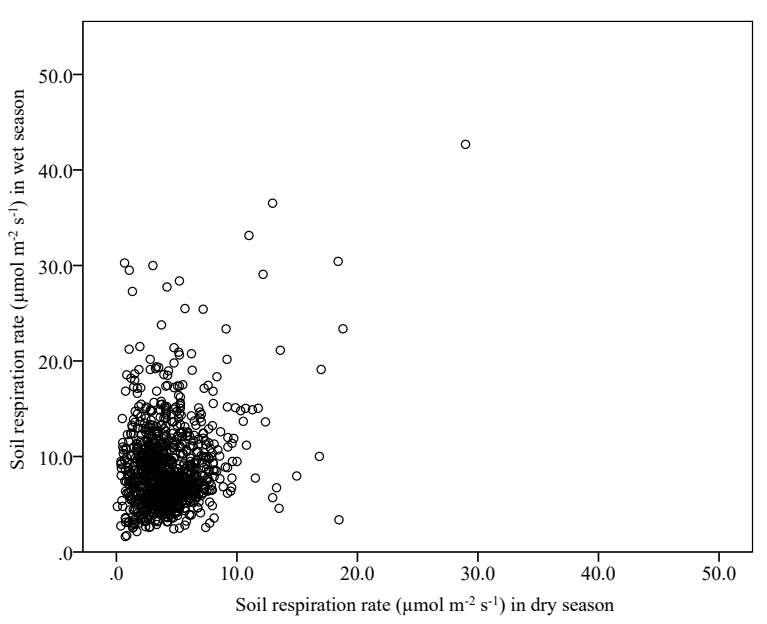

Fig. 5 Correlation of soil respiration rates between dry and wet seasons.

the hot spots $\left(>10 \mu \mathrm{mol} \mathrm{CO} \mathrm{Cm}^{-2} \mathrm{~s}^{-1}\right.$ ) in the tropical forests of Malaysia, contributing to $10 \%$ of the total soil respiration. Moreover, the termite mounds contributed up to $10 \%$ of the total soil respiration in a tropical monsoon forest of Southern Vietnam, showing the maximum rate of the mound $\mathrm{CO}_{2}$ emissions of $20 \mu \mathrm{mol} \mathrm{CO} \mathrm{m}^{-2} \mathrm{~s}^{-1}$ [17]. As the hot spots showed highly temporal and spatial variations, it was proposed to be attributed from unrevealed activities of soil animals, especially social insects (e.g. termites) because it is well known that termites are superabundant soil animals in seasonal tropical forests of Thailand $[10,18]$.

Other studies also reported that both mound and subterranean nest of termites $[16,19,20]$ and ants $[16,21]$ emitted significantly higher $\mathrm{CO}_{2}$ than the surrounding soils. For termite, the mound $\mathrm{CO}_{2}$ emission rate in a tropical savanna was about 10$19 \mu \mathrm{mol} \mathrm{CO} \mathrm{m}^{-2} \mathrm{~s}^{-1}$ compared with 5-10 $\mu \mathrm{mol}$ $\mathrm{CO}_{2} \mathrm{~m}^{-2} \mathrm{~s}^{-1}$ from the surrounding soils [22]. In a tropical forest, the mean of $\mathrm{CO}_{2}$ emission from termite mound was reached up to $27.9 \mu \mathrm{mol} \mathrm{CO}_{2}$ $\mathrm{m}^{-2} \mathrm{~s}^{-1}$, which was much higher than the surrounding soil $\left(3.96 \mu \mathrm{mol} \mathrm{CO} \mathrm{m}^{-2} \mathrm{~s}^{-1}\right)$ [16]. For ant, the $\mathrm{CO}_{2}$ efflux rates from the subterranean nests in the tropical forests reached up to 27.5 [21] and $45.5 \mu \mathrm{mol} \mathrm{CO} \mathrm{Cm}^{-2} \mathrm{~s}^{-1}$ [16]. In addition, other soil organisms, such as earthworms, have no effect on the emission of $\mathrm{CO}_{2}$ from soil $(0.20 \mu \mathrm{mol} \mathrm{CO}$ $\mathrm{m}^{-2} \mathrm{~s}^{-1}$ ) [23]. However, earthworms increased soil carbon content and other nutrients [5] which, as a result, enhanced soil respiration by microbial activities. Since other soil characteristics, such as carbon, nutrients, $\mathrm{pH}$, and soil animal activities, were not investigated in this study, the causes of the hot spots could not be proved.

\section{Effects of temperature and moisture on soil respiration}

Soil respiration, together with soil temperature and soil moisture content, showed strong seasonal variations with higher rates in the hot humid seasons and lower values in the cool dry seasons. The annual soil respiration rates were significantly and positively correlated with both soil temperatures $(R=$ 0.053, $p<0.05)$ and soil moisture contents $(R=$ $0.452, p<0.001$ ) but with a much higher relation with soil moisture. However, this result includes both temporal and spatial variation, which makes it ambiguous between the effects of soil temperature and soil moisture on variability of soil respiration. Therefore, the relationships of soil respiration with soil temperature and soil moisture content in the dry and wet seasons were examined (Fig. 6). The results showed that relationships between soil respiration and soil temperature were significantly negative in the dry season $(R=-0.345, p<0.01)$, but significantly positive in the wet season $(R=$ $0.357, p<0.01)$. While the relationship between soil respiration and soil moisture was significantly positive only in dry season $(R=0.429, p<0.01)$, but showed no significant correlation in the wet season $(R=-0.41, p=0.198)$. The results imply that soil respiration was limited by soil moisture in dry season. This means that the increase in soil temperature (to a very high degree) decreased soil moisture thus reducing soil respiration. In contrast, soil moisture was not a major driving factor in the wet season because there was enough water for soil microbial activities. Therefore, soil temperature (also not so high) was a major factor contributing to the increase of soil respiration in wet season.

Generally, soil respiration rate increases with increasing soil temperature and soil moisture content [24-26], but at certain points, the soil respiration rate could be negatively correlated with soil temperature and soil moisture content. In this study, it was found that soil respiration decreased when soil temperature was higher than $27^{\circ} \mathrm{C}$ in the dry season (Fig. 7a), and when soil moisture content was greater than $21 \%$ in the wet season (Fig. 7b). The finding of $21 \%$ soil moisture cutting point is the same value as what was found in the Western Thailand forest [11], but more than what was found (18\%) in the previous study of DEF at the same site of this study [21]. In wet season, the 

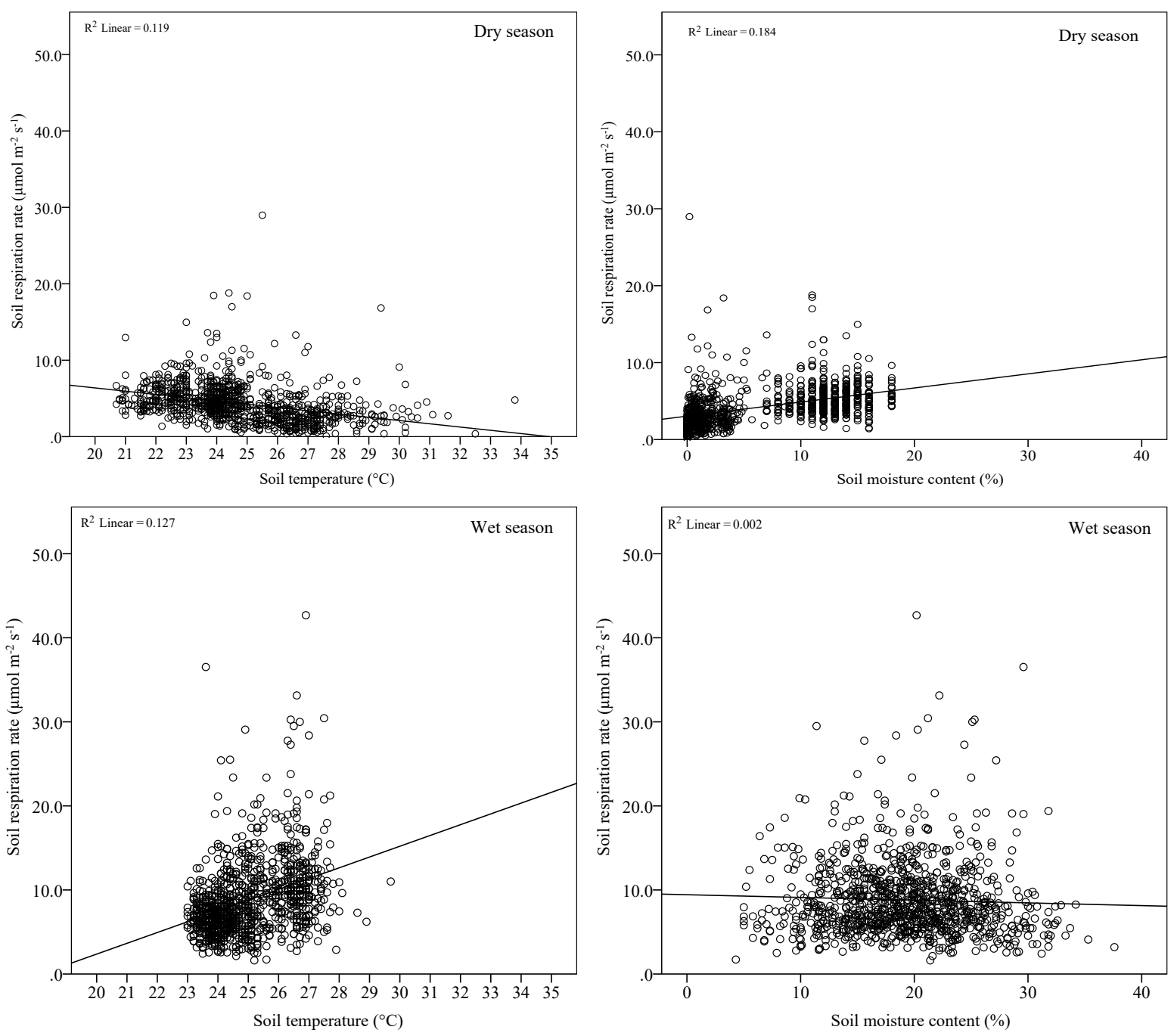

Fig. 6 Changes in soil respiration with soil temperatures and soil moisture contents in dry and wet seasons.
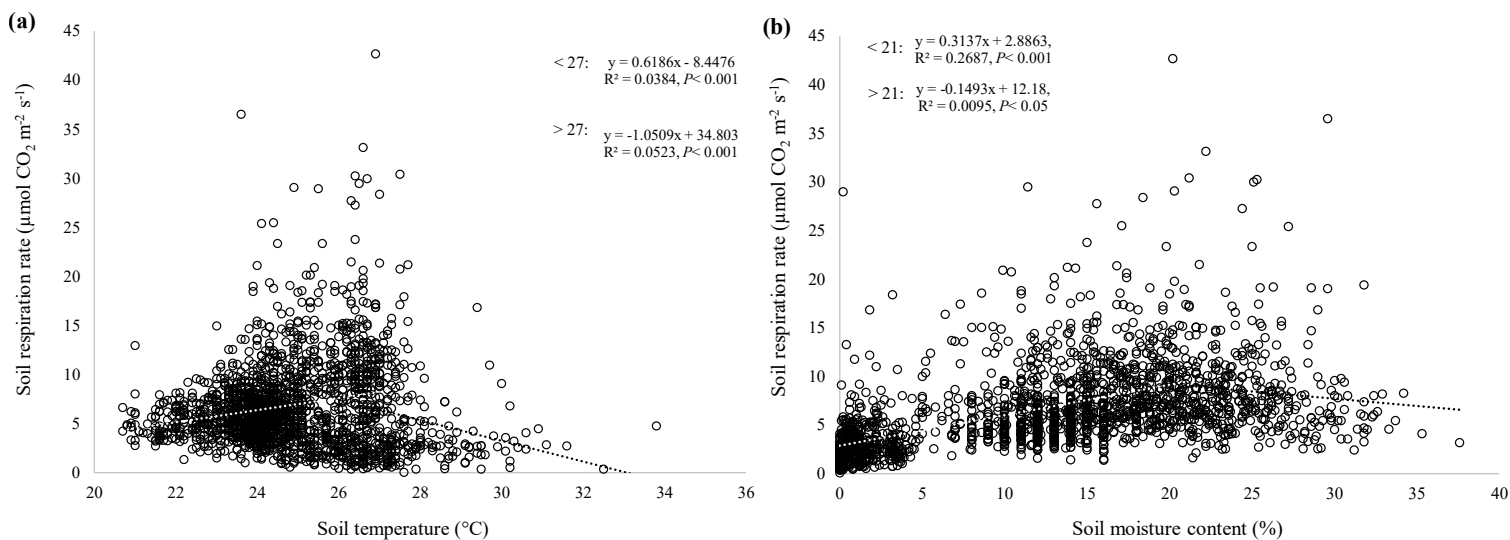

Fig. 7 Relationships between soil respiration and soil temperatures (a) and soil moisture contents (b) for dry and wet seasons. Note the cutting points at $27^{\circ} \mathrm{C}$ soil temperature and $21 \%$ soil moisture content. The regression was run separately for soil temperature $<27^{\circ} \mathrm{C}$ and $>27^{\circ} \mathrm{C}$ and soil moisture content $<21 \%$ and $>21 \%$. 
available precipitation influences soil microbial activities. However, high soil moisture content creates a barrier at the soil atmosphere surface, which could inhibit the diffusion of $\mathrm{CO}_{2}$ out from the soil [13] or lower oxygen in soil texture. This variability in the timing and magnitude of precipitation events can affect soil respiration.

\section{CONCLUSION}

In a seasonal tropical forest, soil respiration was highly variable spatially and temporally. The seasonal change clearly affects soil respiration as it significantly increases in the wet season more than the dry season. Seasons also significantly alter spatial variation of soil respiration. Wet season significantly increases spatial variation of soil respiration as well as soil temperature and soil moisture more than dry season. This study also suggests the importance of other soil features such as soil texture, soil nutrients, and subterranean nests on high $\mathrm{CO}_{2}$ emission locations in order to depict soil respiration at a large scale area, and the results can be applied for tropical forest ecosystems.

Acknowledgements: This work was mainly supported by the Japan Society for the Promotion of Science under Grant-in-Aid for Young Scientists (B) 25850104 (to AY). This study was also financially supported by both Suranaree University of Technology and Thailand Institute of Scientific and Technological Research (TISTR). We are thankful to SERS staff for their advice and support with this study. We thank Kham Youanechuexian, Manuswee Phanichnok, and Ketsada Sala for their assistance during fieldwork.

\section{REFERENCES}

1. Janssens IA, Kowalski AS, Ceulemans R (2001) Forest floor $\mathrm{CO}_{2}$ fluxes estimated by eddy covariance and chamber-based model. Agric For Meteorol 106, 61-69.

2. Chambers JQ, Tribuzy ES, Toledo LC, Crispim BF, Higuchi N, Dos Santos J, Araujo AC, Kraut B, et al (2004) Respiration from a tropical forest ecosystem: partitioning of sources and low carbon use efficiency. Ecol Appl 14, S72-S88.

3. Solomon S, Qin D, Manning M, Chen Z, Marquis M, Averyt KB, Tignor M, Miller HL (2007) Climate Change 2007: The Physical Science Basis, Contribution of Working Group I to the Fourth Assessment Report of the Intergovernmental Panel on Climate Change, Cambridge University Press, UK.

4. Raich JW, Schlesinger WH (1992) The global carbon dioxide flux in soil respiration and its relationship to vegetation and climate. Tellus 4B, 81-99.
5. Lavelle P, Spain A (2001) Soil Ecology, Kluwer Academic Press, New York, USA.

6. Luo Y, Zhou X (2006) Soil Respiration and the Environment, Elsevier, UK.

7. Hashimoto S, Tanaka N, Suzuki M, Inoue A, Takizawa H, Kosaka I, Tanaka K, Tantasirin C, et al (2004) Soil respiration and soil $\mathrm{CO}_{2}$ concentration in a tropical forest, Thailand. $J$ For Res 9, 75-79.

8. Hanson PJ, Edwards NT, Garten CT, Andrews JA (2000) Separating root and soil microbial contributions to soil respiration: A review of methods and observations. Biogeochemistry 48, 115-146.

9. Kanzaki M, Kagotani M, Kawasaki T, Yoda K, Sahunalu P, Dhammanonda P, Prachaiyo B, Thoranisorn S (1995) Forest structure and composition of tropical seasonal forests of Sakaerat Environmental Research Station and the effects of fire protection on a dry deciduous forest. In: Yoda K, Sahunalu P, Kanzaki K (eds) Elucidation of the Missing Sink in the Global Carbon Cycling-Focusing on the Dynamics of Tropical Seasonal Forests, Osaka City University, Osaka, Japan, pp 1-20.

10. Yamada A, Inoue T, Sugimoto A, Takematsu Y, Kumai T, Hyodo F, Fujita A, Tayasu T, et al (2003) Abundance and biomass of termites (Insecta: Isoptera) in dead wood in a dry evergreen forest of Thailand. Sociobiology 42, 569-585.

11. Adachi M, Ishida A, Bunyavejchewin S, Okuda T, Koizumi H (2009) Spatial and temporal variation in soil respiration in a seasonally dry tropical forest, Thailand. $J$ Trop Ecol 25, 531-539.

12. Bulsathaporn A, Suekhum D, Hanpattanakit P, Sanwangsri M, Chidthaisong A, Towprayoon S, Inubushi $\mathrm{K}$, et al (2018) Soil $\mathrm{CO}_{2}$ emissions measured by closed chamber and soil gradient methods in dry dipterocarp forest and sweet sorghum plots. ScienceAsia 44, 1-10.

13. Sotta ED, Meir P, Malhi Y, Nobre AD, Hodnett M, Grace J (2004) Soil $\mathrm{CO}_{2}$ efflux in a tropical forest in the central Amazon. Glob Chang Biol 10, 601-617.

14. Ohashi M, Kume T, Yamane S, Suzuki M (2007) Hot spots of soil respiration in an Asian tropical rainforest. Geophys Res Lett 34, ID L08705.

15. Yoda K, Nishioka M (1982) Soil respiration in dry and wet seasons in a tropical dry-evergreen forest in Sakaerat, NE Thailand. Jap J Ecol 32, 539-541.

16. Ohashi M, Maekawa Y, Hashimato Y, Takematsu Y, Hasin S, Yamane S (2017) $\mathrm{CO}_{2}$ emission from subterranean nests of ants and termites in a tropical rainforest in Sarawak, Malaysia. Appl Soil Ecol 117118, 147-155.

17. De Gerenyu VL, Anichkin A, Avilov V, Kuznetsov A, Kurganova I (2015) Termites as a factor of spatial differentiation of $\mathrm{CO}_{2}$ fluxes from the soils of monsoon tropical forests in southern Vietnam. Eurasian $J$ Soil Sci 48, 208-217.

18. Yamada A, Inoue T, Wiwatwitaya D, Ohkuma M, 
Kudo T, Abe T, Sugimoto A (2005) Carbon mineralization by termites in tropical forests, with emphasis on fungus-combs. Ecol Res 20, 453-460.

19. Brümmer C, Papen H, Wassmann R, Brüggemann N (2009) Fluxes of $\mathrm{CH}_{4}$ and $\mathrm{CO}_{2}$ from soil and termite mounds in south Sudanian savanna of Burkina Faso (West Africa). Global Biogeochem Cycles 23, GB1001.

20. Risch AC, Anderson TM, Schutz M (2012) Soil $\mathrm{CO}_{2}$ emissions associated with termitaria in tropical savanna: Evidence for hot-spot compensation. Ecosystems 15, 1147-1157.

21. Hasin S, Ohashi M, Yamada A, Hashimoto Y, Tasen W, Kume T, Yamane S (2014) $\mathrm{CO}_{2}$ efflux from subterranean nests of ant communities in a seasonal tropical forest, Thailand. Ecol Evol 20, 3929-3939.

22. Konate S, Roux XL, Verdier B, Lepage M (2003) Effect of underground fungus-growing termites on carbon dioxide emission at the point and landscape-scales in African savanna. Funct Ecol 17, 305-314.
23. Guo Y, Zhang X, Zhang Y, Wu D, McLaughlin N, Zhang S, Chen X, Jia S, et al (2019) Temporal variation of earthworm impacts on soil organic carbon under different tillage systems. Int $J$ Environ Res Public Health 16, ID 1908.

24. Xu M, Qi Y (2001) Soil-surface $\mathrm{CO}_{2}$ efflux and its spatial and temporal variations in a young ponderosa pine plantation in northern California. Glob Chang Biol 7, 667-677.

25. Qi Y, Xu M, Wu J (2002) Temperature sensitivity of soil respiration and its effects on ecosystem carbon budget: Nonlinearity begets surprises. Ecol Modell 153, 131-142.

26. Reichstein M, Tenhunen JD, Ourcival JM, Rambal S, Dore S, Valentini R (2002) Ecosystem respiration in two Mediterranean evergreen Holm Oak forests: Drought effects and decomposition dynamics. Funct Ecol 16, 27-39. 